\title{
Imaging Neuroinflammation after Stroke: Current Status of Cellular and Molecular MRI Strategies
}

\author{
Lisette H. Deddens $^{a} \quad$ Geralda A.F. Van Tilborg $^{a} \quad$ Willem J.M. Mulder ${ }^{b}$ \\ Helga E. De Vries ${ }^{c}$ Rick M. Dijkhuizen ${ }^{a}$ \\ aBiomedical MR Imaging and Spectroscopy Group, Image Sciences Institute, University Medical Center Utrecht, \\ Utrecht, The Netherlands, ' Translational and Molecular Imaging Institute, Mount Sinai School of Medicine, \\ New York, N.Y., USA; ' Department of Molecular Cell Biology and Immunology, VU University Medical Center, \\ Amsterdam, The Netherlands
}

\section{Key Words}

Molecular imaging $\cdot$ Cellular imaging $\cdot$ Magnetic resonance imaging $\cdot$ Inflammation $\cdot$ Stroke $\cdot$ Contrast agent

\begin{abstract}
Cellular and molecular magnetic resonance imaging (MRI) strategies for studying the spatiotemporal profile of neuroinflammatory processes after stroke are increasingly being explored since the first reports appeared about a decade ago. These strategies most often employ (super)paramagnetic contrast agents, such as (ultra)small particles of iron oxide and gadolinium chelates, for MRI-based detection of specific leukocyte populations or molecular inflammatory markers that are involved in the pathophysiology of stroke or plasticity. In this review we describe achievements, limitations and prospects in the field of cellular and molecular MRI of neuroinflammation in preclinical and clinical stroke. Several studies in rodent stroke models have demonstrated the application of MRI contrast agents for imaging of monocyte infiltration, which served as the foundation for pilot (smallscale proof-of-concept) cellular MRI studies in stroke patients. This may be achieved with isolated cells that are loaded with contrast agent through in vitro incubation prior to
\end{abstract}

systemic administration. Alternatively, superparamagnetic iron oxide particles may be directly injected into the circulation to allow in vivo uptake by phagocytic cells. Both strategies have been successfully employed to measure the spatiotemporal profile of invasion of monocytes in and around cerebral ischemic lesions in experimental stroke models. Molecular MRI studies with target-specific contrast agents have shown the capability for in vivo detection of molecular markers after experimental stroke. For example, (super)paramagnetic micro- or nanoparticles that are functionalized with a ligand (e.g. an antibody) for specific cell adhesion molecules, such as E-selectin and vascular cell adhesion molecule 1 (VCAM-1), can target inflamed, activated endothelium, whose presence can subsequently be detected with MRI. Present applications remain limited as most of the currently available contrast agents provide relatively poor contrast enhancement, which is not easily discriminated from endogenous sources of tissue contrast. Nevertheless, current developments of more efficient particles, such as biocompatible liposomes, micelles and nanoemulsions that can contain high payloads of (super)paramagnetic material as well as

L.H.D. and G.A.F.V.T. contributed equally to this work.

\section{KARGER}

Fax +4161306 1234

E-Mail karger@karger.ch

www.karger.com (c) 2012 S. Karger AG, Basel

$1015-9770 / 12 / 0334-0392 \$ 38.00 / 0$

Accessible online at:

www.karger.com/ced
Dr. Rick M. Dijkhuizen

Biomedical MR Imaging and Spectroscopy Group, Image Sciences Institute University Medical Center Utrecht, Yalelaan 2

NL-3584CM Utrecht (The Netherlands)

Tel. +31 30253 5569, E-Mail r.m.dijkhuizen@invivonmr.uu.nl 
other substances, such as dyes and drugs, may open a window of opportunities for promising translational multimodal imaging strategies that enable in vivo assessment of (neuroinflammatory) disease markers, therapeutic targets as well as drug delivery after stroke.

Copyright ๑ 2012 S. Karger AG, Basel

\section{Introduction}

Magnetic resonance imaging (MRI) is a versatile imaging modality that is widely applied for stroke diagnosis in clinical and research settings. MRI enables noninvasive and longitudinal monitoring of stroke-induced abnormalities in brain morphology, physiology and function, in patients as well as animal models $[1,2]$. Furthermore, additional use of MR paramagnetic contrast agents allows complementary assessment of vascular flow, tissue perfusion and blood-brain barrier (BBB) integrity [1]. Importantly, the potential of MRI to detect cellular and molecular events at the neurovascular level, which are critically involved in the pathophysiology and plasticity $[3,4]$, has become imminent due to current advancements in contrast agent design and synthesis. For example, cellular labeling and molecular targeting with tailored contrast agents may enable measurement of neuroinflammatory processes such as infiltration of leukocytes and upregulation of markers of endothelial activation, respectively. These developments have facilitated MRI-based detection of inflammatory cells and molecular markers in preclinical stroke studies, and have recently led to the initiation of such studies in human subjects, as will be discussed in this review. The potential to image inflammatory processes could be of particular value for elucidating the complex role of neuroinflammation in the progression of stroke injury, as well as for direct monitoring of (anti-inflammatory) treatment effects.

Cellular and molecular imaging allow direct or indirect monitoring and recording of the spatiotemporal distribution of molecular or cellular processes for biochemical, biological, diagnostic and therapeutic applications [5]. Cellular MRI involves labeling of cells with MRI contrast agents to enable tracking of their migration and distribution in tissues while for molecular MRI, contrast agents are functionalized with ligands (e.g. antibodies) that specifically target molecular markers (fig. 1). MR contrast agents reduce the intrinsic longitudinal $\left(\mathrm{T}_{1}\right)$ and transverse $\left(\mathrm{T}_{2}{ }^{(*)}\right.$ relaxation times of the tissue surrounding these labeled cells, thereby generating localized hyperintense or hypointense areas on $\mathrm{T}_{1^{-}}$or $\mathrm{T}_{2}{ }^{(*)}$-weighted

Cellular and Molecular MRI of

Neuroinflammation after Stroke
MR images, respectively. The potency of a contrast agent to change the signal intensity on MR images is represented by its relaxivities $r_{1}, r_{2}$ and $r_{2}^{*}$, expressed in $\mathrm{mm}^{-1} \cdot \mathrm{s}^{-1}$. In general, the ratio between these relaxivity values determines whether a contrast agent is most suitable for $\mathrm{T}_{1^{-}}$or $\mathrm{T}_{2}{ }^{(*)}$-weighted imaging, i.e. agents with an $\mathrm{r}_{2} / \mathrm{r}_{1}$ ratio between 1 and 2 typically induce strong contrast effects on $\mathrm{T}_{1}$-weighted images, while agents with higher $\mathrm{r}_{2} / \mathrm{r}_{1}$ ratios induce most tissue contrast on $\mathrm{T}_{2}{ }^{(*)}$-weighted images. For a more extensive overview on the properties of MR contrast agents, we refer to Muller et al. [6].

The most commonly applied contrast agents for cellular and molecular MRI purposes are superparamagnetic iron oxide particles, which come in a wide range of sizes and a variety of coatings (table 1) [8]. The popularity of these agents, typically with high $\mathrm{r}_{2} / \mathrm{r}_{1}$ ratios, is predominantly based on their biocompatibility [9] and their capacity to efficiently disturb local magnetic fields, thereby generating localized hypointense areas on $\mathrm{T}_{2}$ - and $\mathrm{T}_{2}{ }^{{ }-}$ weighted MR images to an extent that generally increases with particle concentration, particle size and external magnetic field strength [10]. Another important class of contrast agents is formed by the FDA- and EMEA-approved low molecular-weight paramagnetic gadolinium (Gd) polyaminocarboxylate chelates, e.g. Gd-diethylenetriamine penta-acetic acid (DTPA) and Gd-tetraazacyclododecanetetraacetic acid (DOTA). These agents have $\mathrm{r}_{2} / \mathrm{r}_{1}$ ratios between 1 and 2 and are therefore regularly applied to induce hyperintense signals on $\mathrm{T}_{1}$-weighted MR images.

In the current review, we give an overview of applications of cellular and molecular MRI to assess neuroinflammation in experimental and clinical stroke. Furthermore, we address novel developments in MR contrast agents and imaging that may be valuable for advanced studies on the pathophysiology of stroke.

\section{Cellular MRI of Leukocytes}

The most commonly applied strategy for cellular MRI of neuroinflammation involves labeling of circulating monocytes by systemic administration of iron oxide nanoparticles. Rausch et al. [32] were the first to apply this approach in a model of permanent middle cerebral artery occlusion (MCAO) in rats, where a single dose of ultrasmall particles of iron oxide (USPIO, Sinerem ${ }^{\circledR}$ ) was injected intravenously $5 \mathrm{~h}$ after permanent MCAO. In this study, $\mathrm{T}_{2}$-weighted MRI revealed accumulation of USPIO in the periphery of the lesion as early as $24 \mathrm{~h}$ after 
Fig. 1. Schematic overview of the concept of cellular and molecular MRI of neuroinflammation. Target-specific contrast agents allow detection of upregulated endothelial markers, such as cell adhesion molecules, while infiltrating leukocytes can be detected after specific cell labeling with contrast agents. For a detailed overview of the inflammatory cascade after stroke, we refer to Iadecola and Anrather [7]. Multimodal lipid-based nanoparticles with incorporated MR contrast agent and fluorescent label can be designed for combined MRI and optical imaging of cells or molecular markers.

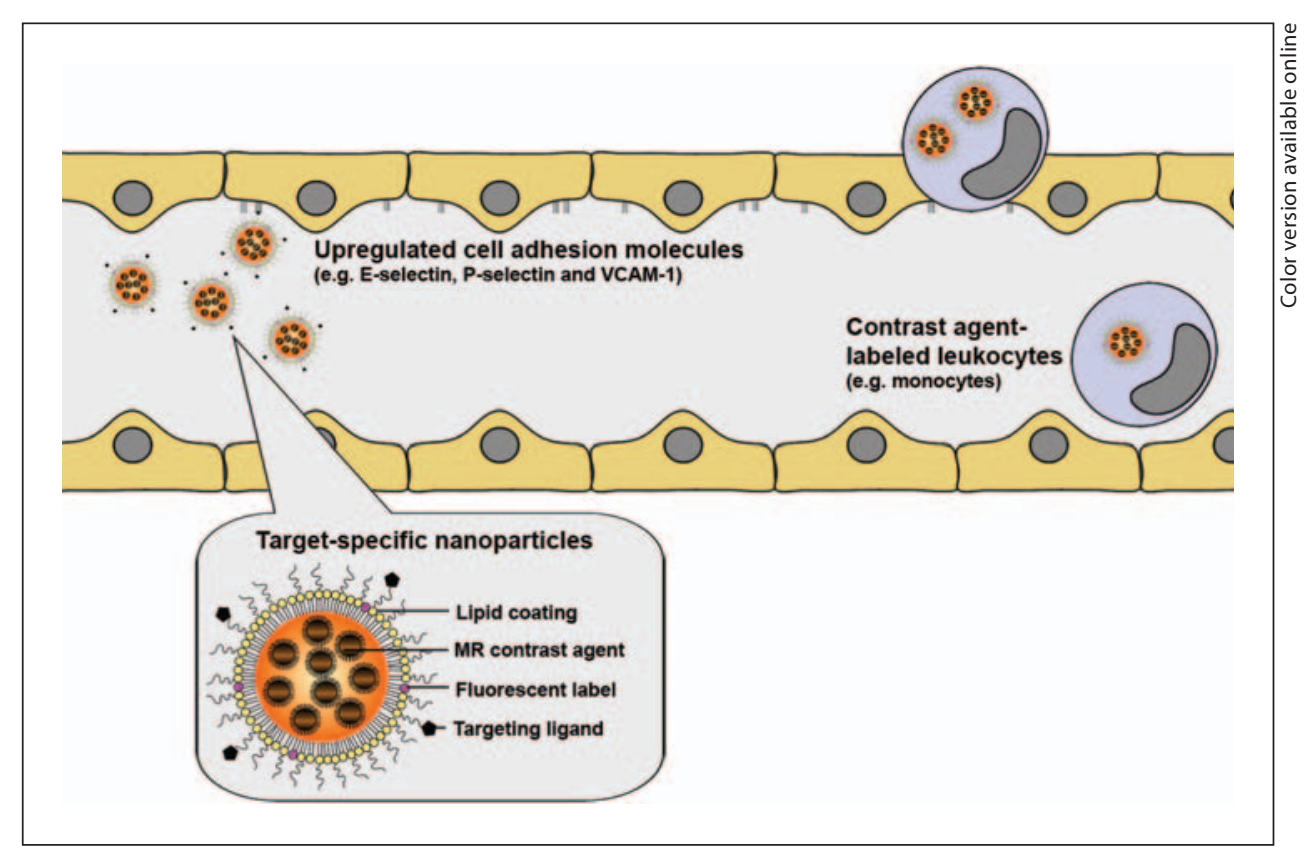

injection. At day 7, USPIO-induced contrast, although decreased and partially redistributed throughout the entire lesion area, was still observed and shown to spatially correlate with regions with activated macrophages. Subsequently, several other groups used a similar approach to assess the spatiotemporal profile of monocyte infiltration in various stroke models in rodents $[15,16,23,33]$. The majority of these studies employed neutrally charged dextran-coated USPIO (Sinerem ${ }^{\circledR} /$ Combidex $^{\circledR}$ ) with a relatively long blood half-life compared to dextran-coated SPIO (Endorem ${ }^{\circledR} /$ Feridex $^{\circledR}$ ) and anionic carboxydextran-coated SPIO (Resovist $\left.{ }^{\circledR}\right)[9,28,44]$. The extended blood half-life is believed to promote the uptake by circulating cells. These in vivo MRI studies have demonstrated that hematogeneous monocyte influx predominantly occurs after several days following the ischemic insult, particularly in the lesion border zone and in some cases extending into the lesion core. These findings of delayed infiltration of blood-borne leukocytes in ischemic lesions are in agreement with data from histological analyses of poststroke brain tissue from bone marrow-chimeric mice [45] and from mice with fluorescently labeled blood cells [13].

The potential of systemically administered USPIO (Sinerem/Combidex) for in vivo imaging of neuroinflammation, as demonstrated in animal studies, has also led to pilot studies in patients suffering from ischemic stroke. Intravenous USPIO (Sinerem) injections at 5-7 days after stroke onset were shown to result in heterogeneously dis- tributed contrast within the lesion area in 100\% [19] or $90 \%$ [17] of the patients. On the other hand, in two other studies, USPIO-induced contrast was observed in only 3 of 9 [20] or 1 of 4 patients [31] when injected at 24-96 h after stroke onset. These MRI studies point out that the infiltration of blood-borne monocytes in stroke lesions is a delayed event.

Although incorporation of contrast agents in activated macrophages and its correlation with MRI contrast have been reported in different studies $[15,16,33]$, there is still debate over whether the observed MRI contrast and ironpositive cells after intravenous injection of iron oxide particles invariably derive from circulating monocytes that encapsulated the contrast agent. First, the labeling efficiency of neutrally charged USPIO (Sinerem/Combidex) in monocytes is considered to be rather poor as demonstrated in several in vitro and in vivo studies $[18,22$, 46-48]. Conversely, the labeling of circulating leukocytes has been shown to significantly increase after intravenous injection of an SPIO/transfection agent (Feridex/ protamine sulfate) complex [48]. Furthermore, monocytes are known to favor the uptake of larger nanoparticles, such as Endorem/Feridex, or charged nanoparticles, such as Resovist [47]. Second, investigations in permanent MCAO and photothrombotic stroke models suggest that early-administered iron oxides may get trapped inside blood vessels, which could be followed by removal of these particles from the damaged area by activated macrophages/microglia $[22,49,50]$. In this case, the presence 
Table 1. Properties of contrast agents used for MRI-based monitoring of inflammation and blood-brain barrier integrity after stroke

\begin{tabular}{|c|c|c|c|c|c|c|c|c|}
\hline $\begin{array}{l}\text { Contrast } \\
\text { agent }\end{array}$ & Manufacturers & $\begin{array}{l}\text { (Super)para- } \\
\text { magnetic } \\
\text { material }\end{array}$ & $\begin{array}{l}\text { Hydrody- } \\
\text { namic diam- } \\
\text { eter, nm }\end{array}$ & Chelate/coating & Charge & $\begin{array}{l}\text { Relaxivities (at } \\
0.47 \mathrm{~T}^{\mathrm{a}} \\
\mathrm{mM}^{-1} \cdot \mathrm{s}^{-1}\end{array}$ & $\begin{array}{l}\text { Blood } \\
\text { half-life } \\
\text { (in rats) }^{\mathrm{b}}\end{array}$ & $\begin{array}{l}\text { Ref. to application } \\
\text { in stroke studies }\end{array}$ \\
\hline Dotarem & Guerbet & gadolinium & $<1$ & $\begin{array}{l}\text { macrocyclic } \\
\text { chelate } \\
\text { (DOTA) }\end{array}$ & anionic & $\begin{array}{l}\mathrm{r}_{1}=3.83-4.74 \\
\mathrm{r}_{2}=5.85[6,11]\end{array}$ & $18 \min [11]$ & {$[22,23]$} \\
\hline VSOP & Ferropharm GmbH & iron oxide & 9 & monomer citrate & anionic & $\begin{array}{l}\mathrm{r}_{1}=19-23 \\
\mathrm{r}_{2}=30-50[24,25]\end{array}$ & $\begin{array}{l}8-86 \min \\
{[26,27]}\end{array}$ & {$[24]$} \\
\hline $\begin{array}{l}\text { Sinerem/ } \\
\text { Combidex }\end{array}$ & $\begin{array}{l}\text { Guerbet/AMAG } \\
\text { Pharmaceuticals }\end{array}$ & iron oxide & $15-35$ & dextran & neutral & $\begin{array}{l}\mathrm{r}_{1}=22-25 ; \\
\mathrm{r}_{2}=44-85[28,29]\end{array}$ & $\begin{array}{l}80 \min -6 \mathrm{~h} \\
{[28-30]}\end{array}$ & $\begin{array}{l}{[13,14,17-20,22,} \\
23,28,31-33]\end{array}$ \\
\hline Resovist & $\begin{array}{l}\text { Bayer Schering } \\
\text { Pharma AG }\end{array}$ & iron oxide & $45-60$ & carboxydextran & anionic & $\begin{array}{l}r_{1}=25 \\
r_{2}=164-177[34,35]\end{array}$ & $13 \min [36]$ & {$[15,16]$} \\
\hline $\begin{array}{l}\text { Dynabeads/ } \\
\text { ProMag }\end{array}$ & $\begin{array}{l}\text { Life Technologies/ } \\
\text { Bangs Laboratories, Inc. }\end{array}$ & iron oxide & $900-3,000$ & variable & variable & $\begin{array}{l}\mathrm{r}_{1}<2 \\
\mathrm{r}_{2}=43[39,40]\end{array}$ & $\begin{array}{l}45-100 \mathrm{~s} \\
{[41,42]}\end{array}$ & {$[43]$} \\
\hline
\end{tabular}

${ }^{a}$ Relaxivities depend on several parameters, including field strength and temperature. ${ }^{b}$ Blood half-life is dependent on the injected dose, and typically increases with dose. Furthermore, the blood half-life of a contrast agent typically decreases after conjugation of a targeting ligand.

of MRI contrast and iron-positive macrophages would not derive from the infiltration of iron-loaded bloodborne monocytes. Third, contrast enhancement may also be caused by general blood pool effects induced by the prolonged presence of a long-circulating contrast agent, such as Sinerem/Combidex [14]. Last, in case of severe $\mathrm{BBB}$ damage, iron oxides may also directly leak into the brain parenchyma [51], where they may be engulfed by activated macrophages/microglia or diffuse into the cerebrospinal fluid (CSF). The latter has been supported by a study in which extensive immunohistological analysis of brain tissue from USPIO (Sinerem)-treated mice at 6 and $24 \mathrm{~h}$ after permanent MCAO revealed internalized USPIO in phagocytes in CSF-bathed areas only [22].

To address the issue of BBB permeability, USPIObased cellular MRI studies in animal models and patients have been combined with Gd-enhanced MRI to correlate USPIO accumulation with BBB integrity. Both in animal stroke models and stroke patients, USPIO contrast appeared to be spatially unrelated to BBB permeability, suggesting that the parenchymal build-up of iron oxides cannot be solely attributed to extravasation over damaged BBB [13, 16, 17, 19, 20].

Alternatively to the approach of labeling within the circulation, cells may also be extracted, subsequently la- beled in vitro and then reinjected. This would allow for more exclusive detection of labeled cells with MRI, avoiding possible nonspecific free iron oxide leakage over the BBB or entrapment in the vasculature. Such a strategy has been applied in stroke models to depict the distribution of mononuclear cells more specifically $[18,24]$. Oude Engberink et al. [18] labeled freshly isolated rat monocytes with SPIO (Endorem) ex vivo; those monocytes were then intravenously injected into rats with photothrombotic stroke lesions. In a different subset of animals, free USPIO (Sinerem) were administered intravenously for comparison. These experiments demonstrated that both strategies resulted in the accumulation of iron oxide in activated monocytes/macrophages/microglia; however, the spatial distribution throughout the lesion differed between the two approaches (fig. 2a). A significant difference in the temporal pattern of MRI contrast enhancement between intravenously injected USPIO and SPIO-labeled monocytes was also evident, with considerable delay in the infiltration of SPIO-labeled monocytes as compared to USPIO (fig. 2b). These data mean that MRI contrast in the region of a stroke lesion following administration of free USPIO may not solely originate from infiltration of monocytes that were labeled within the circulation. 

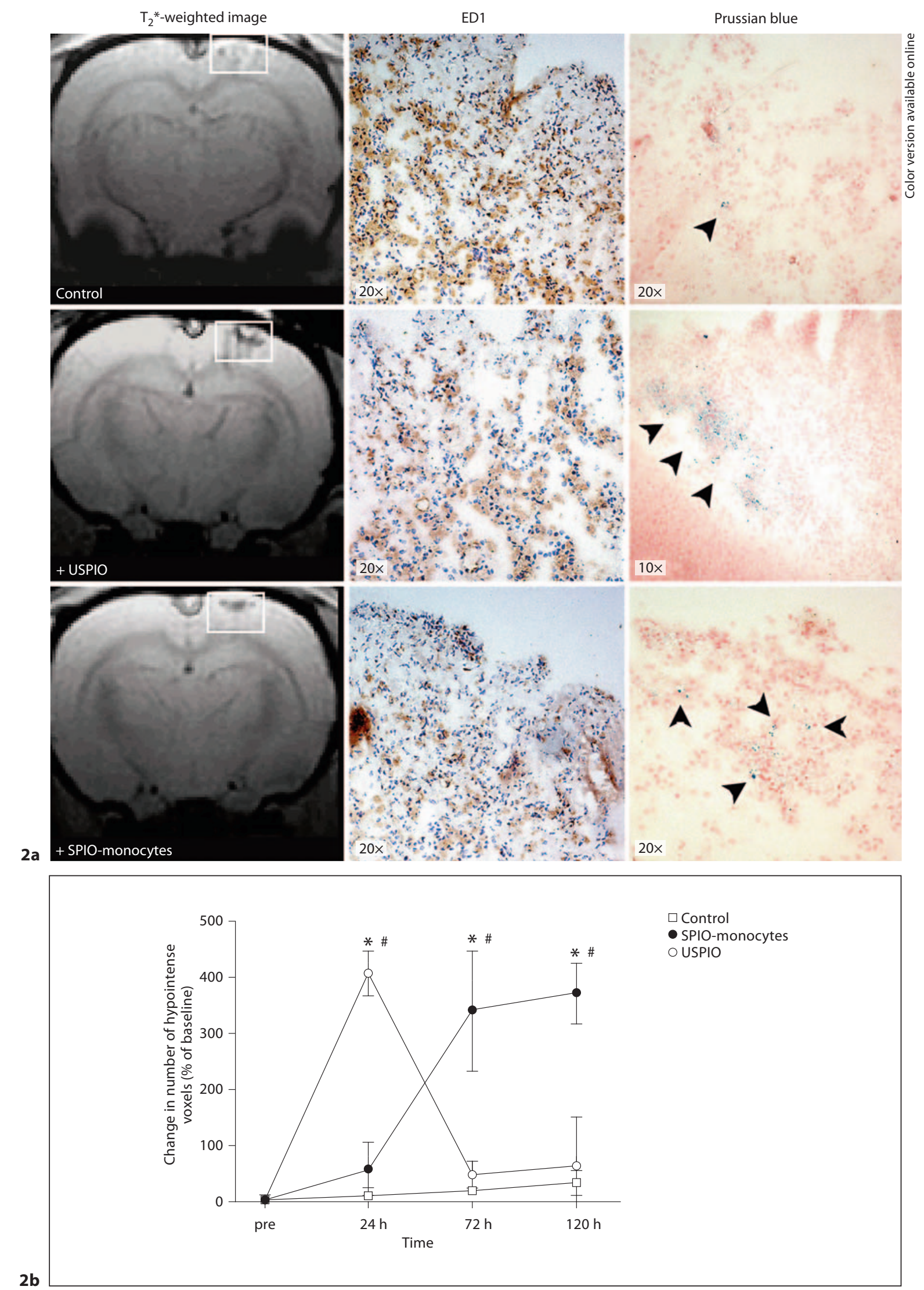
To further circumvent difficulties with in situ labeling of monocytes, Henning et al. [38] applied another labeling approach that had previously been successfully used for MRI of inflammation in a cardiac allograft rejection model [42]. Here, iron oxide particles (Feridex) were intravenously administered in rats 7 days before transient MCAO. Maximum MRI contrast was observed between days 2 and 4 after transient MCAO. In contrast to studies that used an in situ or ex vivo cell-labeling approach, the observed contrast was attributed to labeling of perivascular macrophages instead of activated macrophages $/ \mathrm{mi}$ croglia. Although the exact mechanism remains unclear, it has been suggested that systemically injected iron oxides are taken up by cells of the reticuloendothelial system which may subsequently migrate to sites of inflammation $[41,42,52]$.

As leukocyte influx in a stroke-affected brain is mostly a delayed event, the most logical strategy for cellular imaging studies in animal models of stroke and stroke patients would involve relatively late administration of contrast agents or prelabeled cells. However, at present, most of the traditionally used iron oxide nanoparticles for cellular imaging purposes, such as Sinerem/Combidex, Resovist and Endorem/Feridex, are no longer available. Various alternative types of iron oxide particles are available, however, for the time being, most of them are

Fig. 2. MRI and histology of iron accumulation following intravenous injection of free USPIO or monocytes that were labeled with SPIO (SPIO-monocytes) ex vivo, 5 days after photothrombotic stroke in rats. a $\mathrm{T}_{2}{ }^{*}$-weighted MR images (left column) and brain tissue sections stained for either activated monocytes/macrophages/microglia (ED1+; dark brown; middle column) or iron (Prussian blue; indicated by arrowheads; right column), in a noninjected animal (top row) and in animals $72 \mathrm{~h}$ after injection of free USPIO (middle row) or SPIO-monocytes (bottom row). The presence of ED1+ cells was evident in all groups of animals. In USPIO-injected rats, an iron-positive rim was present in the lesion. In contrast, in animals transfused with SPIO-labeled monocytes, the lesion showed a distinct pattern of iron-positive areas, reflecting the presence of infiltrated SPIO-labeled monocytes. $\mathbf{b}$ Change in the relative number of contrast-enhanced MRI voxels inside the lesion with respect to the preinjection image 24, 72 and $120 \mathrm{~h}$ after the injection. In the USPIO-injected group, the contrast-enhanced area was significantly increased only at $24 \mathrm{~h}$ (* p $<0.05$ vs. SPIO-labeled monocytes). In animals transfused with SPIO-labeled monocytes, the contrast-enhanced area was significantly increased after $72 \mathrm{~h}$, and remained elevated up to $120 \mathrm{~h}$ after injection $\left({ }^{*} \mathrm{p}<0.05\right.$ vs. USPIO). ${ }^{*} \mathrm{p}<0.05$ versus control. Courtesy of Dr. R.D. Oude Engberink. Reprinted from ref. [18] by permission from Macmillan Publishers Ltd.

Cellular and Molecular MRI of

Neuroinflammation after Stroke only applicable for experimental studies. Particles with potential for clinical application include Feraheme ${ }^{\circledR}$ (AMAG Pharmaceuticals), which are $30-\mathrm{nm}$ iron oxide particles with a semisynthetic carbohydrate coating. Currently, Feraheme is only clinically approved for the treatment of iron deficiency anemia in adult patients with chronic kidney disease. However, several studies have shown that Feraheme can also be employed as a contrast agent for MRI [48, 53-55]. Another alternative is P904 (Guerbet), 25- to 30-nm iron oxide particles for which phase I clinical trials have been initiated. Interestingly, both P904 and Feraheme demonstrate significantly higher uptake by macrophages compared to Sinerem $[55,56]$, which is advantageous for cellular-imaging studies. However, the blood half-life of both P904 and Feraheme is shorter than that of Sinerem [55, 57], thereby providing less time for these agents to be engulfed by circulating leukocytes following intravenous administration.

\section{Molecular MRI of Inflammatory Markers}

Infiltration of inflammatory cells in response to brain injury is accompanied by upregulation of inflammatory proteins, such as endothelial cell adhesion molecules, which may also be detected with MRI. MRI of molecular inflammatory markers in rat and mouse brain has been successfully demonstrated in experimental neuroinflammation models, where cytokines were injected intracerebrally [58-60]. These models guarantee high expression of cell adhesion molecules, and may therefore serve in proof-of-principle studies for in vivo detection of targetspecific MR contrast agents. The first study that reported on molecular MRI of neuroinflammation in a stroke model aimed to visualize the upregulation of the endothelial leukocyte adhesion molecules P- and E-selectin [12]. For this purpose, the paramagnetic contrast agent Gd-DTPA (Magnevist ${ }^{\circledR}$ ) was functionalized with a mimetic of sialyl Lewis ${ }^{\mathrm{X}}\left(\mathrm{sLe}^{\mathrm{X}}\right)$, a glycan that binds to P- or E-selectin. Even though changes in longitudinal MR relaxation time $T_{1}$ were relatively modest, $M R$ images revealed specific binding of Gd-DTPA-(sLe $\left.{ }^{\mathrm{X}}\right) \mathrm{A}$ to activated endothelium in the lesion territory $24 \mathrm{~h}$ after transient MCAO in mice. Alternatively, functionalized iron oxide nanoparticles may be applied to enhance contrast effects. This approach has been used by Van Kasteren et al. [60], who designed $\mathrm{sLe}^{\mathrm{X}}$-decorated iron oxide nanoparticles, and by Jin et al. [61], who conjugated a P-selectin-binding peptide to a magnetic iron oxide nanoparticle. Following injection of these targeted nanoparticles, significant hy-

Cerebrovasc Dis 2012;33:392-402 

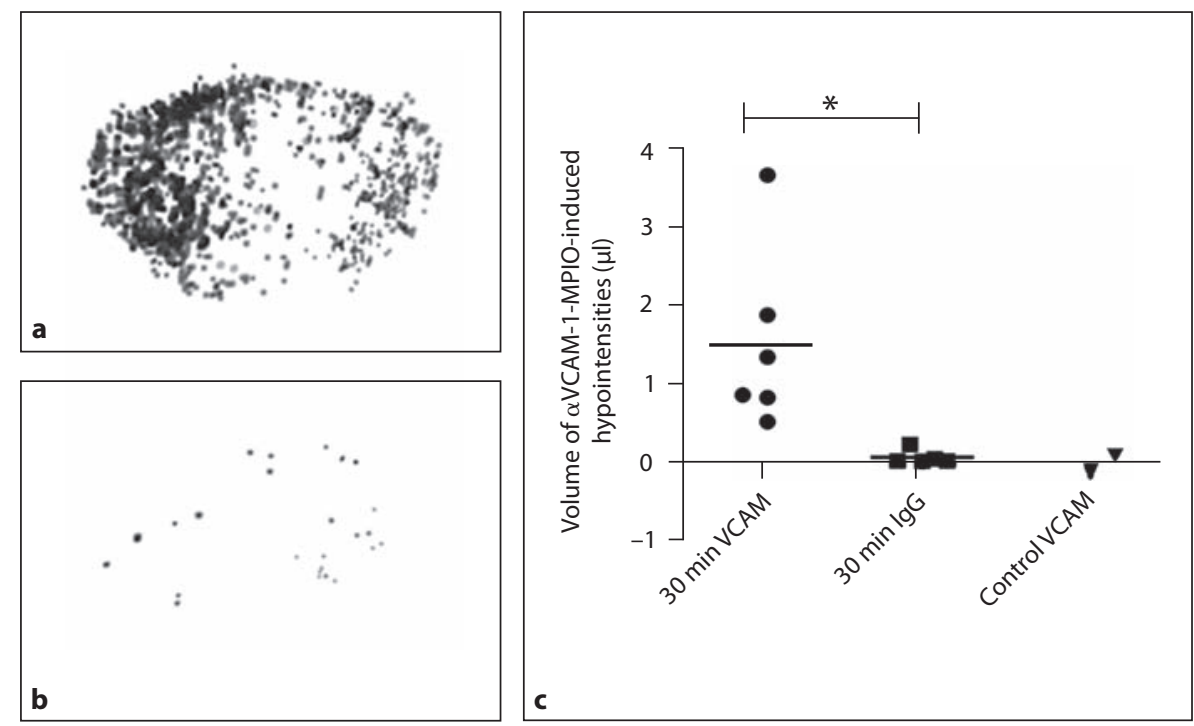

Fig. 3. a $3 \mathrm{D}$ reconstruction of $\alpha \mathrm{VCAM}-1-\mathrm{MPIO}$-induced hypointensities on thresholded $\mathrm{T}_{2}{ }^{*}$-weighted images of mouse brain after $30 \mathrm{~min}$ of MCAO. $\alpha$ VCAM-1-MPIO binding is substantially greater in the ipsilesional hemisphere than in the contralesional hemisphere. b Equivalent 3D reconstruction from an animal injected with the nontargeted IgG-MPIO after $30 \mathrm{~min}$ of MCAO, in which negligible MPIO binding is evident. c Graph illustrating the volumes of MPIO-induced hypointensities in each group of animals. Thirty minutes of MCAO induced binding of $\alpha \mathrm{VCAM}-$ 1-MPIO in the ischemic hemisphere, whilst little MPIO retention was seen in IgG-MPIO-injected animals after 30-min MCAO, and in $\alpha$ VCAM-1-MPIO-injected control animals. ${ }^{*} \mathrm{p}<0.05$. Courtesy of Dr. N.R. Sibson. Reprinted by permission from Macmillan Publishers Ltd from ref. [43]. pointensities on $\mathrm{T}_{2}{ }^{*}$-weighted MR images were observed at sites of primary and secondary injury, a few hours after endothelin-induced stroke in rats [60], and $24 \mathrm{~h}$ after transient $\mathrm{MCAO}$ in mice [61].

Alternatively to P- or E-selectin targeting, Hoyte et al. [43] used an iron oxide-based contrast agent to detect vascular cell adhesion molecule 1 (VCAM-1) upregulation after stroke. In this study, micron-sized particles of iron oxide (MPIO, Dynabeads ${ }^{\circledR}$ ) were functionalized with VCAM-1 antibodies ( $\alpha$ VCAM-1), and intravenously injected $3 \mathrm{~h}$ after transient MCAO in mice. Importantly, isotype control immunoglobulin $\mathrm{G}(\mathrm{IgG})$-functionalized MPIO, of similar size, blood half-life and surface properties as the $\alpha$ VCAM-1-MPIO were administered in a control group. This allowed assessment of possible nonspecific contrast accumulation, for instance as a result of MPIO extravasation through an impaired BBB. $\mathrm{T}_{2}{ }^{*}$ weighted MR images of mice injected with $\alpha \mathrm{VCAM}-1$ MPIO revealed significantly more signal voids in the brain as compared to IgG-MPIO-injected mice, thereby demonstrating the target specificity of the contrast agent (fig. 3). The spatial extent of VCAM-1 expression was found to be considerably larger than the lesion core area detected with diffusion-weighted MRI, and the authors speculated that this approach of molecular MRI of VCAM-1 may reveal both ischemic core and potentially salvageable penumbral regions.

Another promising strategy for molecular MRI involves the use of so-called responsive MR contrast agents. Breckwoldt et al. [21] applied a Gd-based enzyme-activatable agent that induced enhanced $\mathrm{T}_{1}$ relaxation upon reaction with myeloperoxidase (MPO) [62], an enzyme secreted by activated neutrophils and macrophages or microglia. The injection of this MPO-responsive agent in mice after endothelin-induced stroke resulted in prolonged contrast enhancement at the lesion site compared to conventional Gd-DTPA (Magnevist), suggesting that contrast enhancement resulted from additional MPO activity.

\section{Future Directions}

Cellular and molecular MRI are promising, relatively noninvasive methods to image distinct aspects of neuroinflammation following stroke. These approaches not only improve the ability to assess in vivo inflammatory processes in the brain, but also provide a platform for de- 


\begin{tabular}{|c|c|c|c|c|}
\hline Paramagnetic labels & Fluorescent labels & Lipids & Oil & Targeting ligand \\
\hline $\begin{array}{l}\text { Iron oxide } \\
\sigma=\text { Gd-labeled lipid }\end{array}$ & $\begin{array}{l}\text { Quantum dot } \\
\text { = Fluorescent lipid }\end{array}$ & $\begin{aligned} r_{0} & =\text { PEGylated lipid } \\
& =\text { Ordinary } \\
\text { phospholipid } & \\
& \text { Cholesterol }\end{aligned}$ & & - \\
\hline sin & & no & & Emulsion \\
\hline
\end{tabular}

Fig. 4. Schematic representation of different types of lipid-coated nanoparticles with a variety of possible imaging entities, including MRI labels (Gd-labeled lipids or iron oxide) and fluorescent labels (fluorescent lipids or quantum dots), and a targeting ligand. PEGylated lipids typically increase the blood half-life of nanoparticles.

tection of disease biomarkers that are not detectable with conventional MRI. At present, cellular and molecular MRI studies after stroke have largely been limited to imaging of monocytes/macrophages and certain cell adhesion molecules (i.e. P- or E-selectin, and VCAM-1) in the brain. This can be explained by the ease of labeling of phagocytosing monocytes/macrophages as compared to nonphagocytic leukocytes (e.g. T cells) while intraluminally expressed endothelial cell adhesion molecules are readily accessible to intravascularly injected targeted contrast agents as compared to extravascular markers beyond the BBB. Nevertheless, the feasibility of MRI of T cell infiltration $[63,64]$ and other cell adhesion molecules, e.g. ICAM-1 [65], has been demonstrated in experimental models of multiple sclerosis, which suggests that similar preclinical stroke studies may soon ensue.

Despite the promises, one of the challenging aspects that hamper the broad applicability of cellular and molecular MRI is low MR sensitivity. As compared to other molecular imaging modalities, such as PET, SPECT and optical imaging, cellular and molecular MRI require relatively high amounts of contrast agent. Insufficient local accumulation, nanoparticle degradation and label dilution by cell division may each lead to undetectable levels of MR contrast agent. This is particularly an issue for $\mathrm{Gd}$ chelates which typically have a lower contrast efficacy than iron oxides. Furthermore, their $\mathrm{T}_{1}$ effect is quenched upon compartmentalization in cells, thereby limiting their application for cellular imaging studies $[66,67]$.

To increase the efficiency of MR contrast agents, nanoor microformulations can be manufactured with a high payload of contrast agent per unit. MPIO, which contain very high amounts of iron oxide, are an important example of such particles, with sizes in the micrometer range. Commercially available polystyrene/divinylbenzene MPIO such as employed by Hoyte et al. [43] are adequate for preclinical investigations. But these particles are inert, which excludes their application in humans. Recent developments in the synthesis of biodegradable MPIO may potentially provide a clinically applicable alternative [68].

Another established platform for increased contrast payload is available in the form of lipid-based nanoparticles [69]. Lipid-based nanoparticles, such as micelles, emulsions or liposomes, are comprised of a biocompatible lipid mono- or bilayer coating that encapsulates either an aqueous or hydrophilic core (fig. 4). The composition of this lipid coating, as well as the relative amount of additionally incorporated hydrophobic compounds (e.g. oil), defines the morphology, size and blood half-life of the particle [70,71]. This offers an extremely versatile and tunable compound for a wide variety of applications, 
ranging from preclinical cellular and molecular imaging studies to drug delivery in patients [72]. For MRI purposes, large quantities of Gd-containing lipids can be incorporated into the nanoparticle's lipid (bi)layer [73], or alternatively, hydrophobic iron oxide nanocrystals can be encapsulated in the nanoparticle's core $[74,75]$. Moreover, additional inclusion of fluorescent moieties [76] or PET/SPECT tracers [77] in the lipid (bi)layer, or hydrophobic particles, such as gold particles [78] and quantum dots [79], in the nanoparticle core, extends the utility of this platform to multimodal imaging set-ups [80].

In addition to the relatively low potency of most agents to induce MRI contrast, cellular and molecular MRI are further constrained by intrinsic tissue contrast. This is particularly difficult when intrinsic tissue contrast changes, such as under pathophysiological conditions. Stroke-related endogenous sources of MRI contrast, like edema or microbleeds, may lead to deficient or erroneous detection of contrast agent-labeled cells or targeted-specific contrast accumulation. An alternative MRI approach that could circumvent these difficulties involves the use of ${ }^{19} \mathrm{~F}$-containing particles, such as perfluorocarbon emulsions, which have already been successfully applied for the in situ labeling of circulating monocytes [81].
${ }^{19} \mathrm{~F}$ is not naturally present in biological tissues and a ${ }^{19} \mathrm{~F}$ MRI signal can thus be perceived as a direct, quantitative measure of accumulated contrast agent $[81,82]$. However, ${ }^{19} \mathrm{~F}$ MRI requires a specialized hardware setup and tailored imaging protocols, which are currently not available on every (pre)clinical MRI scanner.

Even though the whole range of capabilities and limitations of cellular and molecular MRI has yet to be established, current developments point towards their potential for in vivo assessment of neuroinflammatory processes, and detection of disease biomarkers and therapeutic targets. Future studies in animal models and human subjects, including adequate assessment of safety issues associated with nanoparticle injection, will provide further details on the utility of cellular and molecular MRI in preclinical and clinical stroke.

\section{Acknowledgment}

We gratefully acknowledge funding from the Netherlands Organization for Scientific Research (NWO; VIDI 917.76.347), and the European Union's Seventh Framework Programme (FP7/2007-2013) under grant agreements No. 201024 and No. 202213 (European Stroke Network).

\section{References}

1 Dijkhuizen RM, Nicolay K: Magnetic resonance imaging in experimental models of brain disorders. J Cereb Blood Flow Metab 2003;23:1383-1402.

$\checkmark 2$ Baird AE, Warach S: Magnetic resonance imaging of acute stroke. J Cereb Blood Flow Metab 1998; 18:583-609.

3 Brea D, Sobrino T, Ramos-Cabrer P, Castillo $\mathrm{J}$ : Inflammatory and neuroimmunomodulatory changes in acute cerebral ischemia. Cerebrovasc Dis 2009;27(suppl 1):48-64.

4 del Zoppo GJ: Relationship of neurovascular elements to neuron injury during ischemia. Cerebrovasc Dis 2009;27(suppl 1):65-76.

5 Thakur M, Lentle BC: Report of a summit on molecular imaging. Radiology 2005;236: 753-755.

6 Muller RN, Roch A, Colet JM, Ouakssim A, Gillis P: Particulate magnetic contrast agents; in Merbach AE, Tóth E (eds): The chemistry of contrast agents in medical magnetic resonance imaging. New York, Wiley, 2001, pp 417-435.

7 Iadecola C, Anrather J: The immunology of stroke: From mechanisms to translation. Nat Med 2011;17:796-808.
8 Gossuin Y, Gillis P, Hocq A, Vuong QL, Roch A: Magnetic resonance relaxation properties of superparamagnetic particles. Wiley Interdiscip Rev Nanomed Nanobiotechnol 2009; 1:299-310.

-9 Weissleder R, Stark DD, Engelstad BL, Bacon BR, Compton CC, White DL, Jacobs P, Lewis J: Superparamagnetic iron oxide: pharmacokinetics and toxicity. AJR Am J Roentgenol 1989;152:167-173.

10 Bulte JW, Vymazal J, Brooks RA, Pierpaoli C, Frank JA: Frequency dependence of MR relaxation times. II. Iron oxides. J Magn Reson Imaging 1993;3:641-648.

11 Bousquet JC, Saini S, Stark DD, Hahn PF, Nigam M, Wittenberg J, Ferrucci JT Jr: GdDOTA: characterization of a new paramagnetic complex. Radiology 1988;166:693-698.

12 Barber PA, Foniok T, Kirk D, Buchan AM, Laurent S, Boutry S, Muller RN, Hoyte L, Tomanek B, Tuor UI: MR molecular imaging of early endothelial activation in focal ischemia. Ann Neurol 2004;56:116-120.

13 Denes A, Vidyasagar R, Feng J, Narvainen J, McColl BW, Kauppinen RA, Allan SM: Proliferating resident microglia after focal cerebral ischaemia in mice. J Cereb Blood Flow Metab 2007;27:1941-1953.
14 Farr TD, Seehafer JU, Nelles M, Hoehn M: Challenges towards MR imaging of the peripheral inflammatory response in the subacute and chronic stages of transient focal ischemia. NMR Biomed 2011;24:35-45.

15 Kim J, Kim DI, Lee SK, Kim DJ, Lee JE, Ahn SK: Imaging of the inflammatory response in reperfusion injury after transient cerebral ischemia in rats: correlation of superparamagnetic iron oxide-enhanced magnetic resonance imaging with histopathology. Acta Radiol 2008;49:580-588.

16 Kleinschnitz C, Bendszus M, Frank M, Solymosi L, Toyka KV, Stoll G: In vivo monitoring of macrophage infiltration in experimental ischemic brain lesions by magnetic resonance imaging. J Cereb Blood Flow Metab 2003;23:1356-1361.

17 Nighoghossian N, Wiart M, Cakmak S, Berthezene Y, Derex L, Cho TH, Nemoz C, Chapuis F, Tisserand GL, Pialat JB, Trouillas P, Froment JC, Hermier M: Inflammatory response after ischemic stroke: a USPIO-enhanced MRI study in patients. Stroke 2007; 38:303-307. 
$\checkmark 18$ Oude Engberink RD, Blezer EL, Hoff EI, Van der Pol SM, Van der Toorn A, Dijkhuizen RM, De Vries HE: MRI of monocyte infiltration in an animal model of neuroinflammation using SPIO-labeled monocytes or free USPIO. J Cereb Blood Flow Metab 2008;28: 841-851.

- 19 Saleh A, Schroeter M, Jonkmanns C, Hartung HP, Modder U, Jander S: In vivo MRI of brain inflammation in human ischaemic stroke. Brain 2004;127:1670-1677.

20 Saleh A, Schroeter M, Ringelstein A, Hartung HP, Siebler M, Modder U, Jander S: Iron oxide particle-enhanced MRI suggests variability of brain inflammation at early stages after ischemic stroke. Stroke 2007;38:27332737.

21 Breckwoldt MO, Chen JW, Stangenberg L, Aikawa E, Rodriguez E, Qiu S, Moskowitz MA, Weissleder R: Tracking the inflammatory response in stroke in vivo by sensing the enzyme myeloperoxidase. Proc Natl Acad Sci USA 2008;105:18584-18589.

-22 Desestret V, Brisset JC, Moucharrafie S, Devillard E, Nataf S, Honnorat J, Nighoghossian N, Berthezene Y, Wiart M: Earlystage investigations of ultrasmall superparamagnetic iron oxide-induced signal change after permanent middle cerebral artery occlusion in mice. Stroke 2009;40:1834-1841.

-23 Wiart M, Davoust N, Pialat JB, Desestret V, Moucharrafie S, Cho TH, Mutin M, Langlois JB, Beuf O, Honnorat J, Nighoghossian N, Berthezene Y: MRI monitoring of neuroinflammation in mouse focal ischemia. Stroke 2007:38:131-137.

-24 Stroh A, Zimmer C, Werner N, Gertz K, Weir K, Kronenberg G, Steinbrink J, Mueller S, Sieland K, Dirnagl U, Nickenig G, Endres M: Tracking of systemically administered mononuclear cells in the ischemic brain by high-field magnetic resonance imaging. Neuroimage 2006;33:886-897.

25 Taupitz M, Wagner S, Schnorr J, Kravec I, Pilgrimm H, Bergmann-Fritsch H, Hamm B: Phase I clinical evaluation of citrate-coated monocrystalline very small superparamagnetic iron oxide particles as a new contrast medium for magnetic resonance imaging. Invest Radiol 2004;39:394-405.

-26 Schnorr J, Taupitz M, Wagner S, Pilgrimm H, Hansel J, Hamm B: Age-related blood half-life of particulate contrast material: experimental results with a USPIO in rats. J Magn Reson Imaging 2000;12:740-744.

-27 Taupitz M, Schnorr J, Abramjuk C, Wagner S, Pilgrimm H, Hunigen H, Hamm B: New generation of monomer-stabilized very small superparamagnetic iron oxide particles (VSOP) as contrast medium for MR angiography: Preclinical results in rats and rabbits. J Magn Reson Imaging 2000;12:905911.
8 Rausch M, Baumann D, Neubacher U, Rudin M: In-vivo visualization of phagocytotic cells in rat brains after transient ischemia by uspio. NMR Biomed 2002;15:278-283.

29 Weissleder R, Elizondo G, Wittenberg J, Rabito CA, Bengele HH, Josephson L: Ultrasmall superparamagnetic iron oxide: Characterization of a new class of contrast agents for MR imaging. Radiology 1990;175: 489-493.

30 Chambon C, Clement O, Le Blanche A, Schouman-Claeys E, Frija G: Superparamagnetic iron oxides as positive MR contrast agents: in vitro and in vivo evidence. Magn Reson Imaging 1993;11:509-519.

31 Cho TH, Nighoghossian N, Wiart M, Desestret V, Cakmak S, Berthezene Y, Derex L, Louis-Tisserand G, Honnorat J, Froment JC, Hermier M: USPIO-enhanced MRI of neuroinflammation at the sub-acute stage of ischemic stroke: Preliminary data. Cerebrovasc Dis 2007;24:544-546.

32 Rausch M, Sauter A, Frohlich J, Neubacher U, Radu EW, Rudin M: Dynamic patterns of USPIO enhancement can be observed in macrophages after ischemic brain damage. Magn Reson Med 2001;46:1018-1022.

33 Saleh A, Wiedermann D, Schroeter M, Jonkmanns C, Jander S, Hoehn M: Central nervous system inflammatory response after cerebral infarction as detected by magnetic resonance imaging. NMR Biomed 2004; 17 : 163-169.

34 Wang YX, Hussain SM, Krestin GP: Superparamagnetic iron oxide contrast agents: physicochemical characteristics and applications in MR imaging. Eur Radiol 2001;11: 2319-2331.

35 Qin J, Laurent S, Jo YS, Roch A, Mikhaylova M, Bhujwalla ZM, Muller RN, Muhammed M: A high-performance magnetic resonance imaging $\mathrm{T}_{2}$ contrast agent. Adv Mater 2007; 19:1874-1878.

36 Briley-Saebo KC, Johansson LO, Hustvedt SO, Haldorsen AG, Bjørnerud A, Fayad ZA, Ahlstrom HK: Clearance of iron oxide particles in rat liver: effect of hydrated particle size and coating material on liver metabolism. Invest Radiol 2006;41:560-571.

- 37 Josephson L, Lewis J, Jacobs P, Hahn PF, Stark DD: The effects of iron oxides on proton relaxivity. Magn Reson Imaging 1988;6: 647-653.

-38 Henning EC, Ruetzler CA, Gaudinski MR, Hu TC, Latour LL, Hallenbeck JM, Warach $\mathrm{S}$ : Feridex preloading permits tracking of CNS-resident macrophages after transient middle cerebral artery occlusion. J Cereb Blood Flow Metab 2009;29:1229-1239.

39 Hong R, Cima MJ, Weissleder R, Josephson $\mathrm{L}$ : Magnetic microparticle aggregation for viscosity determination by MR. Magn Reson Med 2008;59:515-520.

-40 Taktak S, Sosnovik D, Cima MJ, Weissleder $\mathrm{R}$, Josephson L: Multiparameter magnetic relaxation switch assays. Anal Chem 2007; 79:8863-8869.
41 Yang Y, Yanasak N, Schumacher A, Hu TC: Temporal and noninvasive monitoring of inflammatory-cell infiltration to myocardial infarction sites using micrometer-sized iron oxide particles. Magn Reson Med 2010;63: 33-40.

42 Ye Q, Wu YL, Foley LM, Hitchens TK, Eytan DF, Shirwan H, Ho C: Longitudinal tracking of recipient macrophages in a rat chronic cardiac allograft rejection model with noninvasive magnetic resonance imaging using micrometer-sized paramagnetic iron oxide particles. Circulation 2008;118:149-156.

43 Hoyte LC, Brooks KJ, Nagel S, Akhtar A, Chen R, Mardiguian S, McAteer MA, Anthony DC, Choudhury RP, Buchan AM, Sibson NR: Molecular magnetic resonance imaging of acute vascular cell adhesion molecule-1 expression in a mouse model of cerebral ischemia. J Cereb Blood Flow Metab 2010;30:1178-1187.

-44 Briley-Saebo KC, Johansson LO, Hustvedt SO, Haldorsen AG, Bjornerud A, Fayad ZA, Ahlstrom HK: Clearance of iron oxide particles in rat liver: Effect of hydrated particle size and coating material on liver metabolism. Invest Radiol 2006;41:560-571.

45 Schilling M, Besselmann M, Leonhard C, Mueller M, Ringelstein EB, Kiefer R: Microglial activation precedes and predominates over macrophage infiltration in transient focal cerebral ischemia: a study in green fluorescent protein transgenic bone marrow chimeric mice. Exp Neurol 2003;183:25-33.

46 Oude Engberink RD, Van der Pol SM, Dopp EA, De Vries HE, Blezer EL: Comparison of SPIO and USPIO for in vitro labeling of human monocytes: MR detection and cell function. Radiology 2007;243:467-474.

47 Metz S, Bonaterra G, Rudelius M, Settles M, Rummeny EJ, Daldrup-Link HE: Capacity of human monocytes to phagocytose approved iron oxide MR contrast agents in vitro. Eur Radiol 2004;14:1851-1858.

48 Wu YJ, Muldoon LL, Varallyay C, Markwardt S, Jones RE, Neuwelt EA: In vivo leukocyte labeling with intravenous ferumoxides/protamine sulfate complex and in vitro characterization for cellular magnetic resonance imaging. Am J Physiol Cell Physiol 2007;293:C1698-1708.

49 Kleinschnitz C, Schutz A, Nolte I, Horn T, Frank M, Solymosi L, Stoll G, Bendszus M: In vivo detection of developing vessel occlusion in photothrombotic ischemic brain lesions in the rat by iron particle enhanced MRI. J Cereb Blood Flow Metab 2005;25: 1548-1555.

50 Bendszus M, Kleinschnitz C, Stoll G: Ironenhanced MRI in ischemic stroke: intravascular trapping versus cellular inflammation. Stroke 2007;38:e12; author reply e13. 
51 Dijkhuizen RM, Asahi M, Wu O, Rosen BR, Lo EH: Rapid breakdown of microvascular barriers and subsequent hemorrhagic transformation after delayed recombinant tissue plasminogen activator treatment in a rat embolic stroke model. Stroke 2002;33:21002104.

52 Montet-Abou K, Daire JL, Hyacinthe JN, Jorge-Costa M, Grosdemange K, Mach F, Petri-Fink A, Hofmann H, Morel DR, Vallee JP, Montet X: In vivo labelling of resting monocytes in the reticuloendothelial system with fluorescent iron oxide nanoparticles prior to injury reveals that they are mobilized to infarcted myocardium. Eur Heart J 2010;31: 1410-1420.

53 Castaneda RT, Khurana A, Khan R, Daldrup-Link HE: Labeling stem cells with ferumoxytol, an FDA-approved iron oxide nanoparticle. J Vis Exp 2011;(57):e3482.

54 Chen S, Alcantara D, Josephson L: A magnetofluorescent nanoparticle for ex-vivo cell labeling by covalently linking the drugs protamine and Feraheme. J Nanosci Nanotechnol 2011;11:3058-3064.

55 Yancy AD, Olzinski AR, Hu TC, Lenhard SC, Aravindhan K, Gruver SM, Jacobs PM, Willette RN, Jucker BM: Differential uptake of ferumoxtran-10 and ferumoxytol, ultrasmall superparamagnetic iron oxide contrast agents in rabbit: critical determinants of atherosclerotic plaque labeling. J Magn Reson Imaging 2005;21:432-442.

56 Corot C, Port M, Guilbert I, Robert P, Raynal I, Robic C, Raynaud JS, Prigent P, Dencausse A, Idée JM: Superparamagnetic contrast agents; in Modo MM, Bulte JW (eds): Molecular and Cellular MR Imaging. CRC Press, 2007, pp 59-83.

57 Sigovan M, Boussel L, Sulaiman A, SappeyMarinier D, Alsaid H, Desbleds-Mansard C, Ibarrola D, Gamondes D, Corot C, Lancelot E, Raynaud JS, Vives V, Lacledere C, Violas $\mathrm{X}$, Douek PC, Canet-Soulas E: Rapid-clearance iron nanoparticles for inflammation imaging of atherosclerotic plaque: Initial experience in animal model. Radiology 2009; 252:401-409.

-58 McAteer MA, Choudhury RP: Chapter 4 Applications of nanotechnology in molecular imaging of the brain. Prog Brain Res 2009; 180:72-96.

59 Sibson NR, Anthony DC, Van Kasteren S, Dickens A, Perez-Balderas F, McAteer MA, Choudhury RP, Davis BG: Molecular MRI approaches to the detection of CNS inflammation. Methods Mol Biol 2011;711:379396.

60 Van Kasteren SI, Campbell SJ, Serres S, Anthony DC, Sibson NR, Davis BG: Glyconanoparticles allow pre-symptomatic in vivo imaging of brain disease. Proc Natl Acad Sci USA 2009;106:18-23.
61 Jin AY, Tuor UI, Rushforth D, Filfil R, Kaur J, Ni F, Tomanek B, Barber PA: Magnetic resonance molecular imaging of post-stroke neuroinflammation with a P-selectin targeted iron oxide nanoparticle. Contrast Media Mol Imaging 2009;4:305-311.

-62 Chen JW, Querol Sans M, Bogdanov A Jr, Weissleder R: Imaging of myeloperoxidase in mice by using novel amplifiable paramagnetic substrates. Radiology 2006;240:473481.

63 Anderson SA, Shukaliak-Quandt J, Jordan EK, Arbab AS, Martin R, McFarland $\mathrm{H}$, Frank JA: Magnetic resonance imaging of labeled t-cells in a mouse model of multiple sclerosis. Ann Neurol 2004;55:654-659.

64 Baeten K, Adriaensens P, Hendriks J, Theunissen E, Gelan J, Hellings N, Stinissen $\mathrm{P}$ : Tracking of myelin-reactive t cells in experimental autoimmune encephalomyelitis (eae) animals using small particles of iron oxide and mri. NMR Biomed 2010;23:601609.

65 Sipkins DA, Gijbels K, Tropper FD, Bednarski M, Li KC, Steinman L: Icam-1 expression in autoimmune encephalitis visualized using magnetic resonance imaging. J Neuroimmunol 2000;104:1-9.

-66 Kok MB, Hak S, Mulder WJ, Van der Schaft DW, Strijkers GJ, Nicolay K: Cellular compartmentalization of internalized paramagnetic liposomes strongly influences both $\mathrm{t} 1$ and $t 2$ relaxivity. Magn Reson Med 2009;61 1022-1032.

67 Terreno E, Geninatti Crich S, Belfiore S, Biancone L, Cabella C, Esposito G, Manazza AD, Aime S: Effect of the intracellular localization of a gd-based imaging probe on the relaxation enhancement of water protons. Magn Reson Med 2006;55:491-497.

68 Nkansah MK, Thakral D, Shapiro EM: Magnetic poly(lactide-co-glycolide) and cellulose particles for mri-based cell tracking. Magn Reson Med 2011;65:1776-1785.

69 Mulder WJ, Strijkers GJ, Van Tilborg GA, Cormode DP, Fayad ZA, Nicolay K: Nanoparticulate assemblies of amphiphiles and diagnostically active materials for multimodality imaging. Acc Chem Res 2009;42:904-914.

70 Klibanov AL, Maruyama K, Torchilin VP, Huang L: Amphipathic polyethyleneglycols effectively prolong the circulation time of liposomes. FEBS Lett 1990;268:235-237.

71 Van Tilborg GA, Strijkers GJ, Pouget EM, Reutelingsperger CP, Sommerdijk NA, Nicolay K, Mulder WJ: Kinetics of avidin-induced clearance of biotinylated bimodal liposomes for improved mr molecular imaging. Magn Reson Med 2008;60:1444-1456.
Torchilin VP: Recent advances with liposomes as pharmaceutical carriers. Nat Rev Drug Discov 2005;4:145-160.

73 Mulder WJ, Strijkers GJ, Griffioen AW, Van Bloois L, Molema G, Storm G, Koning GA, Nicolay K: A liposomal system for contrastenhanced magnetic resonance imaging of molecular targets. Bioconjug Chem 2004; 15: 799-806.

74 Jarzyna PA, Skajaa T, Gianella A, Cormode DP, Samber DD, Dickson SD, Chen W, Griffioen AW, Fayad ZA, Mulder WJ: Iron oxide core oil-in-water emulsions as a multifunctional nanoparticle platform for tumor targeting and imaging. Biomaterials 2009;30: 6947-6954

75 Van Tilborg GA, Mulder WJ, Deckers N, Storm G, Reutelingsperger CP, Strijkers GJ, Nicolay K: Annexin a5-functionalized bimodal lipid-based contrast agents for the detection of apoptosis. Bioconjug Chem 2006; 17:741-749.

76 Mulder WJ, Strijkers GJ, Habets JW, Bleeker EJ, Van der Schaft DW, Storm G, Koning GA, Griffioen AW, Nicolay K: Mr molecular imaging and fluorescence microscopy for identification of activated tumor endothelium using a bimodal lipidic nanoparticle. FASEB J 2005;19:2008-2010.

77 Phillips WT, Goins BA, Bao A: Radioactive liposomes. Wiley Interdiscip Rev Nanomed Nanobiotechnol 2009;1:69-83.

78 Van Schooneveld MM, Cormode DP, Koole R, Van Wijngaarden JT, Calcagno C, Skajaa T, Hilhorst J, t Hart DC, Fayad ZA, Mulder WJ, Meijerink A: A fluorescent, paramagnetic and pegylated gold/silica nanoparticle for mri, ct and fluorescence imaging. Contrast Media Mol Imaging 2010;5:231-236.

79 Mulder WJ, Koole R, Brandwijk RJ, Storm G, Chin PT, Strijkers GJ, De Mello Donega C, Nicolay K, Griffioen AW: Quantum dots with a paramagnetic coating as a bimodal molecular imaging probe. Nano Lett 2006;6: $1-6$.

80 Jarzyna PA, Gianella A, Skajaa T, Knudsen G, Deddens LH, Cormode DP, Fayad ZA, Mulder WJ: Multifunctional imaging nanoprobes. Wiley Interdiscip Rev Nanomed Nanobiotechnol 2010;2:138-150.

-81 Flogel U, Ding Z, Hardung H, Jander S, Reichmann G, Jacoby C, Schubert R, Schrader J: In vivo monitoring of inflammation after cardiac and cerebral ischemia by fluorine magnetic resonance imaging. Circulation 2008;118:140-148.

82 Marsh JN, Hu G, Scott MJ, Zhang H, Goette MJ, Gaffney PJ, Caruthers SD, Wickline SA, Abendschein D, Lanza GM: A fibrin-specific thrombolytic nanomedicine approach to acute ischemic stroke. Nanomedicine (Lond) 2011;6:605-615. 